\title{
A New Social Injustice: Dying Waiting for a Donated Organ
}

\section{Cantarovich $\mathrm{F}^{*}$}

Faculty of Medical Sciences Buenos Aires, Catholic University Argentina, Argentina

*Corresponding author: Felix Cantarovich, Faculty of Medical Sciences Buenos

Aires, Catholic University Argentina, 9 rue Parent de Rosan Paris 75016, France, Tel:

\section{Editorial}

Volume 2 Issue 1

Received Date: January 24, 2019

Published Date: February 01, 2019

DOI: $10.23880 /$ jqhe- 16000109

33145273403; Email: felix.cantarovich@orange.fr

\section{Editorial}

We are nineteen years into the 21st century and patients' mortality rate on waiting lists has increased every year. Undoubtedly, the main factor of this crisis is the persistent insufficient social attitude towards donation [1]. Searching for reason of this people critical behavior, the relative efficiency of social education programs, unchanged since the last decades, should require to be reviewed. Suggestions to change the methodology of social education programs have not been considered by those responsible for the best practice of this medical activity [2-4]. Although the need for a thoughtful change has been pointed out, education programs for organ donation continue to highlight the classic slogan, "Organ donation: a gift of life" [5,6].

Prolonging the life of those requiring a transplant from a living or deceased donor should be a health guarantee for society. Nevertheless, approximately $50 \%$ of the world's population has negative feelings toward organ donation, creating the dilemma of organ shortage. More than 125,000 individuals in the US need a transplant, and approximately every 10 minutes a person is added to a waiting list [7].

McCormick F, et al. point out those 43,000 patients on waiting lists dies every year. The authors note that this is a higher number than that of those dying yearly due to homicide, Parkinson's, or HIV, and roughly similar to the suicide death toll. Kidney shortage kills more people than all gun deaths combined [8].

For these dramatic social problem potential solutions, are suggested. Nevertheless, the possibility to change social attitudes towards donation by developing new education programs is not, as a rule, considered to be a response to the dilemma of organ shortage.
Organ shortage, causing every day the "unfairly" dead of patients is a social, psychological, ethical, moral, and political problem. The unjustifiable reality is that society is denying other humans the chance to continue living.

Since organ transplantation symbolizes turning death into life, the question is why humanity is committing this crime against itself. Undoubtedly, people's acceptance of this catchphrase, requires education programs based on clear comprehension of the main mechanisms of the decision to donate.

Searching to solve this crisis, legal, medical, and educational options have been suggested. Proposals for legal solutions have been based mainly on changing informed consent to presumed consent, as well as economic incentives to donors or donor families. These legal proposals are controversial and difficult to be evaluated [9]. Concerning legal modifications of organ donation consent, mainly at the time of a next of kin death, we consider that only rational and well-organized social education will be able to change the feelings that society reveres at the mourning of death of a loved one.

Regarding medical solutions, the persistent increase in patients "unfairly dying" on waiting lists regardless of the progress of long-term patient and graft has required substantial changes in the acceptance criteria of organ donors. Two of these advances, consequence of research development and improvement of organ procurement organizations, have provided a great benefit to patients.

We should mention the kidney exchange program. This program consists of the possibility of the donor replacement between two couples in order to offer a transplant opportunity to patients who cannot accept 


\section{Journal of Quality in Health Care \& Economics}

their own donor mainly due to immunological incompatibilities [10]. Another medical solution, resulting from the technical advances of organ procurement organizations, is the use of cardio-circulatory dead (DCD) donors, also called non-heart-beating organ transplant. DCD has been accepted internationally and could contribute to an increase of $20 \%$ or more in the supply of kidneys and other solid organs.

On the other hand, the crisis in organ donation supply warrants reconsideration of the option to use organs, no matter the risk for possible substandard survival. This change in medical criteria involves the acceptance of donors currently known as expanded criteria donors (ECD). These donors were previously called marginal or sub-optimal, because their long-term results are lower than those obtained with standards donors [11]. However, taking into account the invariable persistence of organ shortage and considering that ECD organ transplantation significantly increases the survival of waiting-list patients, the acceptance of these donors is ethically justified [12].

In terms of alternatives to improve people's attitudes toward donation, even though an adequate education strategy may change people's attitude toward organ donation, this option has never been attempted [13]. Organ shortage is directly related to the insufficient willingness to donate, a possible consequence of the inadequate role of current education programs. Unfortunately, although an adequate education strategy may change people's attitude toward organ donation, society's education methodology has remained practically unchanged [14]. In addition, the influence of media programs, often reporting harmful misinformation about clinical death and illegal transplantation stories, should also be taken into consideration to evaluate the insufficient public response to organ donation $[15,16]$.

A methodological change in social education concerning organ donation, based on modifications of the current message to society, may be a way to deal with this dilemma. First and foremost, concerning persistent "organ shortage," a primary issue is to analyze if the slogan "organ donation is a gift" should be the basic concept in social education programs about donation.

Concerning this question, it has been noted that unawareness and misinformation, which have always been considered major causes of poor social response, are not essential inhibitions to organ donation. Studies have assigned prevalence to the impact of non-cognitive factors on the final decision to donate $[17,18]$. In this regard, it has been shown that beliefs such as fear of death, mutilation, and a distrust of medical conduct are the main causes of people's negative attitude towards donation [19].

Given the potential importance of non-cognitive factors in affecting social attitudes towards organ donation, we propose the following slogans for future strategies for social education:

- The shortage of organs is a health emergency.

- Throughout our lives, we are all potential recipients of organs and tissues.

- The body after death is a unique source of health for all.

- Organ donation is not giving life; it is sharing life.

- The people acceptance of the belief that organ donation is to share life, may be a tacit agreement for society welfare.

Particularly, we suggest that the catchphrase "The body after death is a unique source of health for all," through a highly structured education, might help overcome the strong inhibition toward donation induces by fear of death and mutilation.

Evaluating the potential role of education towards donation, we share with Schoenberg the primary importance that will have to educating young people from primary schools. Rational curriculums on organ donation and transplantation beginning in elementary schools and continuing at the college and university levels might be an encouraging alternative to change social attitudes towards organ donation [20]. The rationale of this proposal is that young people are free of prejudice and may sometimes learn new ideas more easily than adults. In addition, it has been found that new ideas learned by children in school can be transferred to their families [21].

Experiences in Argentina and Canada showed that the understanding of this critical subject by children aged 10 to 16 years was remarkable. These education attempts suggested that a universal transplantation school curriculum, with messages that might change critical social attitudes toward organ and tissue donation, should be actively considered by state officials responsible for education and public health [5,22-24].

This analysis makes clear that persistent organ shortage is an acute health crisis, evidenced by people's persistent negative attitude toward organ donation. Current permanent organ shortage incriminates society behavior, as the main responsible for a permanent global crisis of health and well-being. To date, measures to solve this problem have been based exclusively on medical or legal solutions. 


\section{Journal of Quality in Health Care \& Economics}

There is evidence that social education programs have not been effective through the years. The search for a solution to this serious crisis justifies any rational attempt based on research and experience. A change to educational programs on organ donation at the social level has never been attempted. This critical reality practically unchanged over the years generates a significant question: It is not the time to seriously revaluate social education programs towards donation?

\section{References}

1. Shmugarajahadan $\mathrm{K}$, Villania $\mathrm{V}$, Madariaga $\mathrm{ML}$, Shalhoubd J, Michelab SG (2014) Current progress in public health models addressing the critical shortage. Int J of Surgery 12(12): 1363-1368.

2. Mocan N, Tekin E (2007) The determinants of the willingness to donate an organ among young adults: evidence from the United States and the European Union. Soc Sci Med 65(12): 2527-2538.

3. Hanto DW, Peters TG, Howard RJ, Cornell D (2005) Family disagreement over organ donation. Virtual Mentor 7 (9): pii: virtualmentor.2005.7.9.ccas2-0509.

4. Verheijde JL, Rady MY, McGregor JL (2007) Negative attitudes and feelings of well- educated people about organ donation for transplantation. Transplant Inter 20(10): 906-907.

5. Cantarovich F (2014) Education and Organ Donation. Potential Role of School Programs. : Abstract\# C2087. Transplantation 98: 838.

6. Humphries HL, Conrad BK, Berry R, Reed S, Jennings CM (2009) Framing the gift of life: An empirical examination of altruism, social distance and material incentives in non-directed kidney donor motivation. J Nephrol Soc Work 31: 19-26.

7. (2017) Organ donation: 10 minutes. 22 people. 54 percent. Perelman School of Medicine at the University of Pennsylvania. Science Daily.

8. McCormic F, Held PJ, Chertow M (2018) The Terrible Toll of the Kidney Shortage. J Am Soc Nephrol 29(12): 2775-2776.

9. Abadie A, Gay S (2006) The impact of presumed consent legislation on cadaveric organ donation: A cross-country study. Journal of Health Economics 25(4): 599-620.
10. Gebel H, Bray R (2008) Approaches for transplanting the sensitized patient: biology versus pharmacology. Nephrol Dial Transplant 23(8): 2454-2457.

11. Alexander JW, Zola JC (1996) Expanding the donor pool: use of marginal donors for solid organ transplantation. Clin Transplant 10(1): 1-19.

12. Cronin AJ (2013) Ethical and legal issues related to the donation and use of nonstandard organs for transplants. Anesthesiol Clin 31(4): 675-687.

13. Davis, John (1991) Davis Surgeon General's Workshop on Increasing Organ Donation, pp: 91-143.

14. Chatterjee P, Venkataraman AS, Vijayan A, Wellen JR, Martin EG (2015) The effect of state policies on organ donation and transplantation in the United States. JAMA Intern Med 175(8): 1323-1329.

15. Aykas A, Uslu A, Şimşek C (2015) Mass media, online social network, and organ donation: old mistakes and new perspectives. Transplant Proc 47(4): 1070-1072.

16. Morgan SE, Harrison TR, Long SD, Afifi WA, Stephenson MT, et al. (2005) Family discussions about organ donation: how the media influences opinions about donation decisions. Clin Transplant 19(5): 674-682.

17. Morgan SE, Harrison TR, Afifi WA, Long SD, Stephenson MT (2008) In their own words: the reasons why people will (not) sign an organ donor card. Health Comm 23(1): 23-33.

18. Morgan SE, Stephenson MT, Harrison TR, Aifi WA, Long SD (2008) Facts versus 'Feelings': how rational is the decision to become organ donor?. J Health Psychol 13 (5): 644-658.

19. O'Carroll RE, Foster C, McGeechan G, Sandford K, Ferguson E (2011) The "ick" factor, anticipated regret, and willingness to become an organ donor. Health Psychol 30(2): 236-245.

20. Shoenberg RS, Robert E (1991) The Reports of the Surgeon General. The Surgeon General's Workshop on Increasing Organ Donation: Background Papers. "Planting the Seed: Organ Transplantation Education for Children, Youth and Young adults", pp: 181-198.

21. Aboud FE, Tredoux C, Tropp LR, Spears Brown C, Niens $U$, et al. (2012) Interventions to reduce prejudice and enhance inclusion and respect for 


\section{Journal of Quality in Health Care \& Economics}

ethnic differences in early childhood: A systematic review. Dev Rev 32(4): 307-336.

22. Gonzalez Mena J, Pulido Tobiassen D (1999) Teaching diversity: a place to begin. Early Childhood Today.

23. Cantarovich F (2010) Organ Donation and a new message for all ages: our body is a source of Life to be shared. TTS International Congress. Societal Public Policy.

24. Cantarovich F, Cantarovich M, Falco E, Revello R, Legendre Ch, et al. (2010) Education on organ donation and transplantation in elementary and high schools: formulation of a new proposal. Transplantation 89(9): 1167-1168. 